\title{
No evidence of conspecific brood parasitism provoking egg rejection in thrushes
}

\author{
Manuel Soler ${ }^{1,2}$
}

A response to: Samas et al.: Host responses to interspecific brood parasitism: a by-product of adaptations to conspecific parasitism? Frontiers in Zoology 2014, 11:34.

Egg rejection is the most common and effective defence used by hosts against brood parasites that lay their eggs in host nests [1]. Interspecific brood parasitism (IBP hereafter) generally imposes high fitness costs on hosts, given that parasitic females usually eat or destroy some host eggs, and parasitic nestlings frequently evict all host offspring or outcompetes most of them for food [1]. Therefore, it is assumed that these strong selection pressures have favoured the evolution of egg-rejection behaviour [1].

Samas et al. [2] have concluded that egg discrimination in thrushes (Turdus spp.; potential hosts of the common cuckoo (Cuculus canorus)) has evolved as a response to conspecific brood parasitism (CBP hereafter) and not to IBP. This conclusion, challenging conventional theory, has far-reaching implications in the field of brood parasitism and therefore should be assessed with caution. The experimental design and methodologies used by Samas et al. are appropriate; however, their conclusions are not valid because their predictions are based on an out-of-date theoretical background and/or a biased selection of references. This assertion is based on the four points discussed below.

First, contrary to what is stated by Samas et al. CBP and IBP do not produce the same antiparasitic adaptations for two main reasons: parasitic and host eggs are very similar, making recognition much more difficult to evolve than in hosts of interspecific brood parasites, and while IBP hosts suffer dramatic fitness costs, costs endured by CBP hosts are much lower, this reducing the strength of selection for defences to evolve [3]. Current empirical evidence shows that CBP almost never selects for egg rejection in altricial species [4].

Correspondence: msoler@ugr.es

'Departamento de Zoología, Facultad de Ciencias, Universidad de Granada, E-18071 Granada, Spain

${ }^{2}$ Grupo Coevolución, Unidad Asociada al CSIC, Universidad de Granada, Granada, Spain
Second, predictions by Samas et al. [2] are based on the statement that host defences have to disappear in the absence of the selection pressures that favoured them. I agree that this is a major prediction of evolutionary theory; however, it is well known that a trait which does not decrease individual fitness may be maintained in the absence of its selection pressure [5], and references therein. Samas et al. ignored numerous studies showing that many currently non-parasitized potential host species present a rejection rate of nearly $100 \%$, which has been retained over long periods of time, and a review that concluded, first, that it is not correct to formulate predictions assuming that rejection behaviour has to disappear in a host population in the absence of brood parasites; and second, that it is inaccurate to assume an effect of the coexistence with brood parasites and/or phenotypic plasticity in general in host species when formulating predictions [6].

Third, Samas et al. [2] assume that thrushes have not been involved in long-term co-evolution with the common cuckoo. However, aggression towards cuckoo dummies and reluctance to feed common cuckoo nestlings has been experimentally demonstrated in thrushes [7], which is a clear indication of past parasitism.

Fourth, the fact that CBP has been documented in thrushes is considered by Samas et al. to be one of the lines of evidence supporting their conclusion that egg rejection evolved in response to CBP instead to IBP. However, reported rates of $\mathrm{CBP}$ are extremely low. In the Samas et al. study populations, CBP rates are $0 \%$ and $2.2 \%$ for the song thrush (T. philomelos) and 3.1\% and $0 \%$ for the blackbird (T. merula) in the areas of sympatry and allopatry with the cuckoo, respectively [2]. Can percentages of CBP of this magnitude support the hypothesis that egg recognition evolved to counter CBP? Samas et al. did not discuss this crucial question. Perhaps the best way to answer it is by using the signal-detection model of Davies et al. [8], as Underwood et al. did [9]. For the black-billed magpie (Pica hudsonia), these authors estimated that the level of CBP in order to select for conspecific egg rejection should be at least $32.5 \%$. Clearly, CBP rates found by 
Samas et al. in song thrushes and blackbirds are far from these values. Furthermore, percentages reported by Samas et al. for blackbirds are the opposite of those expected according to the predictions of these authors.

In conclusion, Samas et al. [2] have demonstrated that rejection rate by song thrushes and blackbirds is higher and latency of rejection lower in New Zealand than in Europe; but these results cannot support the claim that thrushes evolved egg discrimination in response to CBP.

\section{Competing interests}

The author declares that he has no competing interests.

\section{Acknowledgments}

I thank Juan J. Soler for useful and constructive comments on this manuscript; Tomas Grim and Mark E. Hauber for discussions and David Nesbitt for improving the English. Financial support has been provided by the Spanish Ministerio de Economía y Competitividad/FEDER (research project CGL2011-25634/BOS) and by the Junta de Andalucía (research project CVI-6653).

Received: 2 September 2014 Accepted: 4 September 2014 .

\section{References}

1. Davies NB: Cuckoos, Cowbirds and other Cheats. London: T \& AD Poyser; 2000

2. Samas $P$, Hauber ME, Cassey $P$, Grim $T$ : Host responses to interspecific brood parasitism: a by-product of adaptations to conspecific parasitism? Front Zool 2014, 11:34

3. Petrie M, Møller AP: Laying eggs in others nests-intraspecific brood parasitism in birds. Trends Ecol Evol 1991, 6:315-320.

4. Soler M, Ruiz-Castellano C, Fernández-Pinos MC, Rösler A, Ontanilla J, Pérez-Contreras T: House sparrows selectively eject parasitic conspecific eggs and incur very low rejection costs. Behav Ecol Sociobiol 2011, 65:1997-2005

5. Peer BD, Sealy SG: Fate of grackle (Quiscalus spp.) defenses in the absence of brood parasitism: implications for long-term parasite-host coevolution. Auk 2004, 121:1172-1186.

6. Soler M: Long-term coevolution between avian brood parasites and their hosts. Biol Rev 2014, 89:688-704.

7. Grim T, Samas P, Moskát C, Kleven O, Honza M, Moksnes A, Røskaft E, Stokke BG: Constraints on host choice: why do parasitic birds rarely exploit some common potential hosts? J Anim Ecol 2011, 80:508-518.

8. Davies NB, Brooke ML, Kacelnik A: Recognition errors and probability of parasitism determine whether reed warblers should accept or reject mimetic cuckoo eggs. Proc R Soc Lond B 1996, 263:925-931.

9. Underwood TJ, Sealy SG, McLaren CM: Experiments on egg discrimination in two North American corvids: further evidence for retention of egg ejection. Can J Zool 2004, 82:1399-1407.

\section{doi:10.1186/s12983-014-0068-7}

Cite this article as: Soler: No evidence of conspecific brood parasitism provoking egg rejection in thrushes. Frontiers in Zoology 2014 11:68.

\section{Submit your next manuscript to BioMed Central and take full advantage of:}

- Convenient online submission

- Thorough peer review

- No space constraints or color figure charges

- Immediate publication on acceptance

- Inclusion in PubMed, CAS, Scopus and Google Scholar

- Research which is freely available for redistribution 